\title{
Tumor Vascular Permeability Factor Stimulates Endothelial Cell Growth and Angiogenesis
}

\author{
Daniel T. Connolly," Deborah M. Heuvelman, * Rick Nelson," Jitka V. Olander," Barry L. Eppley, \\ John J. Delfino, ${ }^{*}$ Ned R. Slegel, " Richard M. Leimgruber," and Joseph Feder* \\ *Department of Cell Culture and Biochemistry, Central Research Laboratories, Monsanto Company, St. Louis, Missouri 63167; \\ and ${ }^{\ddagger}$ Division of Oral-Maxillofacial Surgery, St. John’s Mercy Medical Center, St. Louis, Missouri 63141
}

\begin{abstract}
Vascular permeability factor (VPF) is an $M_{\mathbf{r}}$ 40-kD protein that has been purified from the conditioned medium of guinea pig line 10 tumor cells grown in vitro, and increases fluid permeability from blood vessels when injected intradermally. Addition of VPF to cultures of vascular endothelial cells in vitro unexpectedly stimulated cellular proliferation. VPF promoted the growth of new blood vessels when administered into healing rabbit bone grafts or rat corneas. The identity of the growth factor activity with VPF was established in four ways: (a) the molecular weight of the activity in preparative SDS-PAGE was the same as VPF $\left(M_{\mathrm{r}} \sim 40 \mathrm{kD}\right)$; (b) multiple isoforms (pI $\geq 8$ ) for both VPF and the growth-promoting activity were observed; (c) a single, unique $\mathrm{NH}_{2}$-terminal amino acid sequence was obtained; $(d)$ both growth factor and permeabilityenhancing activities were immunoadsorbed using antipeptide IgG that recognized the amino terminus of VPF. Furthermore, ${ }^{125} I-V P F$ was shown to bind specifically and with high affinity to endothelial cells in vitro and could be chemically crosslinked to a high-molecular weight cell surface receptor, thus demonstrating a mechanism whereby VPF can interact directly with endothelial cells. Unlike other endothelial cell growth factors, VPF did not stimulate $\left[{ }^{3} \mathbf{H}\right]$ thymidine incorporation or promote growth of other cell types including mouse 3T3 fibroblasts or bovine smooth muscle cells. VPF, therefore, appears to be unique in its ability to specifically promote increased vascular permeability, endothelial cell growth, and angiogenesis.
\end{abstract}

\section{Introduction}

The observation that blood vessels in and around tumors display increased permeability toward plasma fluid and proteins (1-4) has led to the thesis that tumor cells secrete factors that act to increase vessel permeability (5). In support of this idea, a vascular permeability factor $(\mathrm{VPF})^{1}$ was identified and puri-

Address reprint requests to Dr. Daniel T. Connolly, Department of Cell Culture and Biochemistry, Monsanto Company, 800 North Lindbergh Blvd., St. Louis, MO 63167.

Received for publication 30 November 1988 and in revised form 12 April 1989.

1. Abbreviations used in this paper: BAE, bovine aortic endothelial cells; EGF, epidermal growth factor; FBS, fetal bovine serum; FGF, fibroblast growth factor; HUE, human umbilical vein endothelial cells; NEpHGE, nonequilibrium $\mathrm{pH}$ gradient electrophoresis; PDGF, platelet-derived growth factor; TGF, transforming growth factor; TNF, tumor necrosis factor; VPF, vascular permeability factor.

J. Clin. Invest.

(c) The American Society for Clinical Investigation, Inc.

$0021-9738 / 89 / 11 / 1470 / 09 \$ 2.00$

Volume 84, November 1989, 1470-1478 fied from the conditioned medium of guinea pig line 10 tumor cells grown in vitro $(6,7,7 \mathrm{a})$. The $\mathrm{NH}_{2}$-terminal amino acid sequence of VPF has been shown to be unrelated to other proteins for which sequence information is available, including those other proteins that are known to affect vessel permeability (7a). That the unique sequence was VPF associated was confirmed by experiments using antipeptide antibodies to block permeability enhancement (7a). The physiological relevance of VPF was suggested in experiments using antibody prepared against the $M_{\mathrm{r}} 34-42-\mathrm{kD}$ protein that inhibited ascites fluid accumulation in tumor-bearing guinea pigs (6). Although the physical and pharmacological properties of VPF suggested that its action was distinct from other known vasoactive agents such as bradykinin, leukokinins, plasma kallikrein, complement factors $\mathrm{C} 3 \mathrm{a}$ or $\mathrm{C} 5 \mathrm{a}$, histamine or prostaglandins, the mechanism of VPF-mediated permeability enhancement is not known. VPF did not degranulate mast cells. Its action was rapid (within $5 \mathrm{~min}$ ) and transient (diminished by $20 \mathrm{~min}$ ), and endothelium was not damaged. VPFs with similar immunocross-reactivity have been detected in conditioned media from a variety of human and rodent tumor cell lines (8).

The purpose of this study was to determine the direct effects of VPF on endothelial cells. The results reported here demonstrate that VPF is a specific growth factor for vascular endothelial cells in culture, that VPF binds with high affinity to an endothelial cell surface protein, possibly a VPF receptor, and that VPF promotes blood vessel growth in vivo.

\section{Methods}

$V P F$ purification. VPF was purified from cultures of guinea pig line 10 tumor cells $(6,7,7 \mathrm{a})$. Cells were grown in large scale suspension culture in DME with $10 \%$ FCS. Cells were resuspended in serum-free medium for $\mathbf{4 8} \mathrm{h}$, and the medium chromatographed on a column of heparinSepharose (Pharmacia Fine Chemicals, Piscataway, NJ) essentially as described in reference 6 . The Miles assay (9) was used to assay activity. Active fractions were dialyzed against $0.01 \mathrm{M}$ sodium phosphate $(\mathrm{pH}$ 6.1), loaded onto a SP-5-PW cation exchange column and eluted with a gradient of sodium chloride. Active fractions were then chromatographed on $\mathrm{C}_{4}$ and $\mathrm{C}_{18}$ reverse-phase HPLC columns using gradients of acetonitrile in $0.1 \%$ (vol/vol) trifluoroacetic acid (7a).

Cell culture. Bovine aortic endothelial (BAE) cells (clone JV017A) and bovine smooth muscle cells (clone FCSM9) were isolated as described (10) and were grown in DME plus $10 \%$ calf serum. Bovine chondrocytes (INT) were isolated by collagenase digestion of calf cartilage and grown in DME plus 10\% fetal bovine serum (FBS). Mouse fibroblasts (Balb/3T3) grown in DME plus $10 \%$ calf serum and human fetal lung fibroblasts (W138) and mouse meyelomonocytes (WEHI-3), each grown in DME plus $10 \%$ fetal bovine serum were from the American Type Culture Collection (Rockville, MD). Human peripheral lymphocytes (GM892) grown in DME plus 10\% fetal bovine serum were from the Genetic Mutant Cell Repository, The Institute for Medical Research, Camden, NJ. Human umbilical vein endothelial (HUE) cells were isolated by published procedures $(11,12)$, established in 
MCDB131 medium (13), and subcultured in MCDB107 medium (14) supplemented with $10 \% \mathrm{FBS}, 90 \mu \mathrm{g} / \mathrm{ml} \mathrm{Na}$ heparin, $30 \mu \mathrm{g} / \mathrm{ml}$ Endothelial Cell Growth Supplement (Collaborative Research Inc., Lexington, MA), $10 \mathrm{ng} / \mathrm{ml}$ epidermal growth factor (EGF), $1 \mu \mathrm{g} / \mathrm{ml}$ hydrocortisone on human fibronectin-coated tissue culture vessels.

Rabbit bone angiogenesis assay. Angiogenesis was monitored in a healing bone graft model (15). New Zealand white rabbits received autologous bone grafts from the iliac crest (donor site) to the mandibular body (recipient site). Blocks of cortical bone from the ileum $(1 \times 1$ $\mathrm{cm}$ ) were split into two $0.5 \times 1 \mathrm{~cm}$ segments, the central cancellous areas were removed, and the cortex perforated multiple times to provide pores. 14-d sustained-release osmotic pumps (model M-2001; Alza Corp., Palo Alto, CA) were loaded with either $0.24 \mathrm{ml}$ sterile saline containing $75 \mu \mathrm{g}$ VPF and $0.1 \%$ (wt/vol) rabbit serum albumin or the albumin solution (vehicle) alone. The end of the tubing was perforated with a needle to provide multiple outlet points and placed into a channel in the bone, and the graft was placed into the recipient site in the mandible. Each animal received an experimental graft with VPF infusion, and a contralateral graft with infusion of vehicle alone. After $14 \mathrm{~d}$, the blood vessels of the head were cleared by perfusion through the carotid arteries with heparinized saline. The vessels were then perfused with the orange silicone rubber compound Microfil (Canton Biomedical, Boulder, $\mathrm{CO}$ ). After fixation, dehydration, and clearing in methysalicylate, grafts were cut in half and visualized microscopically.

Rat cornea angiogenesis assay. The rat cornea angiogenesis assay was performed as described (16) by Dr. S. Joseph Leibovich, Northwestern University (Chicago, IL). VPF $(4.2 \mu \mathrm{g})$ was lyophilized in the presence of $100 \mu \mathrm{g} \mathrm{BSA}$, resuspended in water at appropriate dilutions, and mixed with equal volumes of Hydron solution. Droplets of the sample/Hydron mixtures $(10 \mu \mathrm{l})$ were placed on the cut ends of 2-mm-diam Teflon dowels for $1 \mathrm{~h}$. The resultant pellets were cut into two, each pellet thus being of defined size. Identical pellets to serve as controls were prepared from $100 \mu \mathrm{g}$ albumin alone, which was lyophilized and diluted as with the VPF/albumin preparation. Corneal pockets were prepared in anesthetized Wistar F233 rats, and a pellet inserted in each pocket. After $7 \mathrm{~d}$, animals were perfused intraarterially with colloidal carbon and the corneas were fixed and photographed.

$\mathrm{NH}_{2}$-terminal amino acid sequence analysis. Automated Edman degradation was performed with a gas phase sequencer and PTH analyzer (models 470A and 120A, respectively; Applied Biosystems, Inc., Foster City, CA). Computer searches were performed using a "fast a" program to probe National Biomedical Research Foundation (Bethesda, MD) and Genbank protein sequence data bases.

Antipeptide antibodies and immunoadsorption. A peptide corresponding to the 21 -amino acid $\mathrm{NH}_{2}$-terminal sequence of guinea pig VPF was synthesized by conventional automated solid-phase peptide synthesis and purified using rapid-phase-(RP)-HPLC (7a). Amino acid analysis was used to confirm the identity of this peptide that consisted of the following sequence:

\section{A PMAEGEQKPREVVKFMDVYK}

$\begin{array}{llll}5 & 10 & 15 & 20\end{array}$

The peptide was conjugated to thyroglobulin using glutaraldehyde, and used for immunization of rabbits. The antiserum used in this study (rabbit F003) had a 50\% dilution titer of 1:3,000-5,000 in a VPF ELISA, and blocked activity in the Miles assay at a dilution of 1:500. For immunoadsorption, $200 \mu \mathrm{l}$ of protein A-Sepharose was incubated for $1 \mathrm{~h}$ at room temperature with $400 \mu \mathrm{l}$ of serum. The protein A-Sepharose was washed three times with $1 \mathrm{ml}$ PBS and incubated with VPF at $4^{\circ} \mathrm{C}$ for $24 \mathrm{~h}$. The supernatants were removed, diluted appropriately, and assayed for permeability enhancement or growth promotion of endothelial cells. Controls were performed using rabbit antiserum prepared against FBS (anti-FBS serum).

Two-dimensional electrophoresis and nonequilibrium $\mathrm{pH}$ gradient electrophoresis (NEpHGE). NEpHGE was performed under nondenaturing conditions using the following conditions. Cylindrical poly- acrylamide gels were cast containing $4 \%$ acrylamide $(4.0 \% \mathrm{~T}, 5.7 \% \mathrm{C})$, $15 \%(\mathrm{vol} / \mathrm{vol})$ glycerol, and $2.1 \%(\mathrm{wt} / \mathrm{vol}$ ) ampholytes (pH 3.5-9.5; LKB Instruments, Gaithersburg, MD). The acrylamide and glycerol were deionized with mixed-bed ion-exchange resin (model RG501-X8; Bio-Rad Laboratories, Richmond, $\mathrm{OH}$ ) immediately before casting the gels. Samples containing VPF were dried in vacuo, dissolved in $10 \%$ glycerol, $1.0 \%$ (wt/vol) ampholyte $\mathrm{pH} 3.5-9.5$, and applied at the anodic end of the gel. Electrophoresis was performed at $400 \mathrm{~V}$ for $30 \mathrm{~min}$, and $500 \mathrm{~V}$ for the final hour $(925 \mathrm{~V} / \mathrm{h}$ total $)$ at $10.5^{\circ} \mathrm{C}$. The anolyte was $0.015 \mathrm{M} \mathrm{H}_{3} \mathrm{PO}_{4}$ and the catholyte was $0.02 \mathrm{M} \mathrm{NaOH}$ (degassed). Two-dimensional gel electrophoresis was performed using NEpHGE as the first dimension. After NEpHGE, the gels were incubated in 62.5 $\mathrm{mM}$ Tris $\mathrm{HCl}, 2.3 \%$ (wt/vol) SDS, $5 \%$ (vol/vol) $\beta$-mercaptoethanol, $\mathrm{pH}$ 6.8 with agitation at room temperature for $10 \mathrm{~min}$. The gels were then embedded in $1 \%$ agarose containing the Tris-SDS-mercaptoethanol equilibration buffer layered on top of a $10 \%$ polyacrylamide slab gel. The second dimension, SDS-PAGE, was run using the conditions of Laemmli (18). Protein was detected by staining with silver (19). Preparative NEpHGE gels were run using the same conditions as the first-dimension gels and either stained or sliced into 2.5 -mm-thick sections that were extracted with $200 \mu \mathrm{l}$ of saline for $1 \mathrm{~h}$ at $37^{\circ} \mathrm{C}$.

Other materials. EGF was from Sigma Chemical Co. (St. Louis, MO). Platelet-derived growth factor (PDGF), IL $1 \alpha$, IL $1 \beta$, and IL 2 were obtained from Collaborative Research. Basic fibroblast growth factor (bFGF) was purified as described (17). Transforming growth factor $\beta$ (TGF $\beta$ ) was from Dr. Joseph De Larco (Monsanto Co., St. Louis, MO), acidic fibroblast growth factor (aFGF) was from Dr. J. Huang (St. Louis University School of Medicine) or from Collaborative Research, and tumor necrosis factor/cachectin (TNF) was from Dr. Philip Pekala (School of Medicine, East Carolina University, Greenville, NC).

\section{Results}

Effect of VPF on endothelial cell growth in vitro. Guinea pig VPF was purified from serum-free line 10 tumor cell-conditioned medium using heparin-Sepharose chromatography, cation exchange HPLC, $\mathrm{C}_{4}$ HPLC, and $\mathrm{C}_{18} \operatorname{HPLC}(6,7,7 \mathrm{a})$. The yield was $\sim 1 \mu \mathrm{g}$ of VPF per liter of conditioned medium. Fractions from the final reverse-phase HPLC column that displayed activity in the Miles permeability assay (9) contained a closely spaced group of protein bands of $M_{\mathrm{r}} 38-40 \mathrm{kD}$ when analyzed in nonreducing gels by SDS-PAGE and silver staining (Fig. $1 A$ ). In reducing gels, VPF migrated as $M_{\mathrm{r}} 20$ - and 24-kD subunits (not shown). These results confirm those of Senger et al. $(6,7 \mathrm{a})$ who showed both by staining and by activity measurements that nonreduced VPF is an $M_{\mathrm{r}}=34-42$ $\mathrm{kD}$ protein

Fig. $1 B$ shows a Miles assay in which different amounts of VPF were injected intradermally into a guinea pig, thereby causing leakage of Evan's blue dye from nearby blood vessels into the tissues as evidenced by the presence of blue spots at the sites of injection. Increased permeability was observed with as little as $1 \mathrm{nM}(8 \mathrm{ng})$ VPF. In experiments in which purified VPF was added to cultures of BAE cells, cell number increased in response to VPF. To determine if this mitogenic activity was due to VPF, a preparation was subjected to SDS-PAGE, gel slices extracted, and the extract assayed for growth-promoting activity. Fig. $1 C$ shows that the growth promoting activity was restricted to the $M_{\mathrm{r}} 40 \mathrm{kD}$ fraction and coincided both with the band in the silver-stained gel and with the permeability-enhancing activity (assay not shown). This is in contrast with the heparin-binding FGFs that are endothelial cell mitogens of lower molecular weight (21). Both activities appear to be asso- 

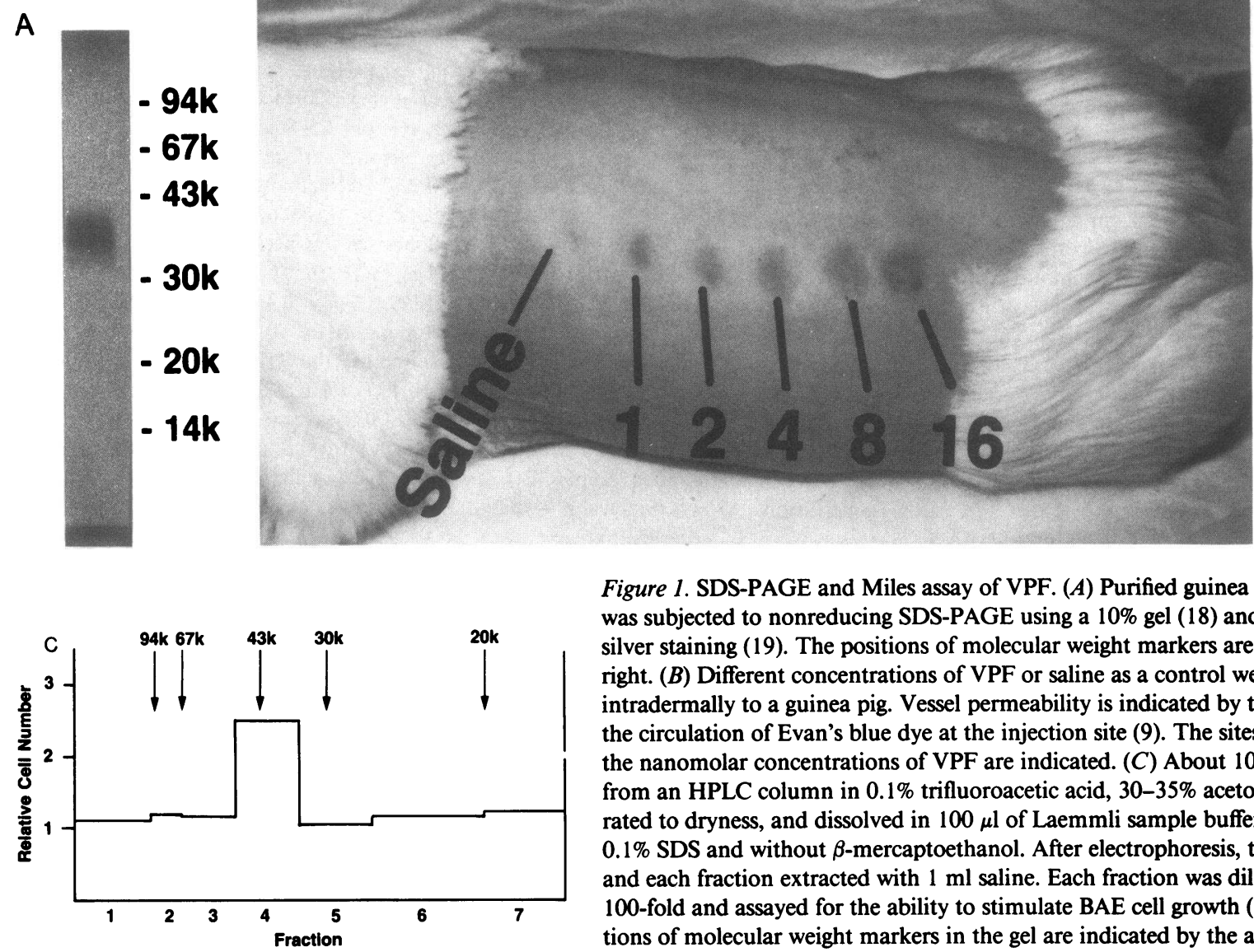

Figure 1. SDS-PAGE and Miles assay of VPF. (A) Purified guinea pig VPF $(0.5 \mu \mathrm{g})$ was subjected to nonreducing SDS-PAGE using a $10 \%$ gel (18) and detected with silver staining (19). The positions of molecular weight markers are shown on the right. $(B)$ Different concentrations of VPF or saline as a control were administered intradermally to a guinea pig. Vessel permeability is indicated by the leakage from the circulation of Evan's blue dye at the injection site (9). The sites of injection and the nanomolar concentrations of VPF are indicated. (C) About $10 \mu \mathrm{g}$ VPF eluted from an HPLC column in $0.1 \%$ trifluoroacetic acid, $30-35 \%$ acetonitrile was evaporated to dryness, and dissolved in $100 \mu$ l of Laemmli sample buffer (18) with only $0.1 \%$ SDS and without $\beta$-mercaptoethanol. After electrophoresis, the gel was sliced and each fraction extracted with $1 \mathrm{ml}$ saline. Each fraction was diluted an additional 100 -fold and assayed for the ability to stimulate BAE cell growth $(10,20)$. The positions of molecular weight markers in the gel are indicated by the arrows.

ciated with the VPF protein. Even though VPF migrated as disperse bands in SDS-PAGE, a single dominant $\mathrm{NH}_{2}$-terminal amino acid sequence was obtained through 36 cycles of Edman degradation:

\section{APMAEGEQKPREVVKFMDVYKRSYCRPIEMLVDIFQ}

$\begin{array}{lllllll}5 & 10 & 15 & 20 & 25 & 30 & 35\end{array}$

Residues 1-24 correspond exactly to those reported earlier (7a). Within the dominant sequence, secondary sequences were observed corresponding to des-amino acid 1 (23\% of total) and des-amino acids $1-3$ (7\% of total). Different preparations of VPF contained variable amounts of the degraded forms. Comparison of this sequence with other known sequences has not revealed obvious similarity to other proteins including permeability enhancers or growth factors (7a).

Further evidence that the growth factor activity is derived from VPF itself was obtained using antipeptide IgG that recognizes the amino-terminal portion of VPF. Rabbit polyclonal antiserum was prepared against a 21-amino acid synthetic peptide containing the VPF sequence. A partially purified preparation of VPF was incubated with immunoadsorbants that were prepared using protein A-Sepharose that had been preincubated with either antipeptide serum or anti-FBS serum as control. Different dilutions of the supernatant were then added to BAE cell cultures and assayed for proliferative activity (Fig. 2). The control immunoadsorbant removed a portion of the activity, as evidenced by displacement of the dose-response curve toward higher concentrations, but treatment with antipeptide immunoadsorbant displaced the curve significantly further. It can be calculated from the concentrations required for $50 \%$ maximal stimulation that $>95 \%$ of the activity was specifically removed by the antipeptide IgG as compared with control IgG.

Charge heterogeneity of VPF. Preliminary attempts to characterize VPF by isoelectric focusing were unsuccessful, probably due to the extremely basic isoelectric point of VPF. Instead, nonequilibrium conditions that prevented VPF from migrating to the cathode were used. Fig. 3 shows two-dimensional electrophoresis of VPF with NepHGE in the first dimensional and SDS-PAGE in the second dimension. Figs. 3, $A$ and $B$ show gels of nonreduced and reduced samples, respectively. In the nonreduced silver-stained gel (Fig. $3 A$ ), a cluster of bands with molecular weights between $\sim M_{\mathrm{r}} 34$ and $43 \mathrm{kD}$ with apparent pIs $\geq 8.0$ are observed. Thus, in addition to the size heterogeneity centered $\sim M_{\mathrm{r}} 40 \mathrm{kD}$ noted in Fig. 1, VPF exhibited extensive charge heterogeneity. Bands outside of this cluster are absent, providing further evidence of the purity of VPF. Upon reduction of disulfide bonds (Fig. $3 \mathrm{~B}$ ), VPF migrated as multiple-subunit bands between $\sim M_{\mathrm{r}} 18$ and $24 \mathrm{kD}$. Note that it has been previously shown that all of the size forms of purified VPF in both reduced and nonreduced Western blots are recognized by antipeptide antibody, and thus contain the same $\mathrm{NH}_{2}$-terminal sequence. The basic isoelectric point of the VPF isoforms are consistent with the ability of VPF to bind tightly to a cation exchange column at $\mathrm{pH} 7.0$ during purification. 


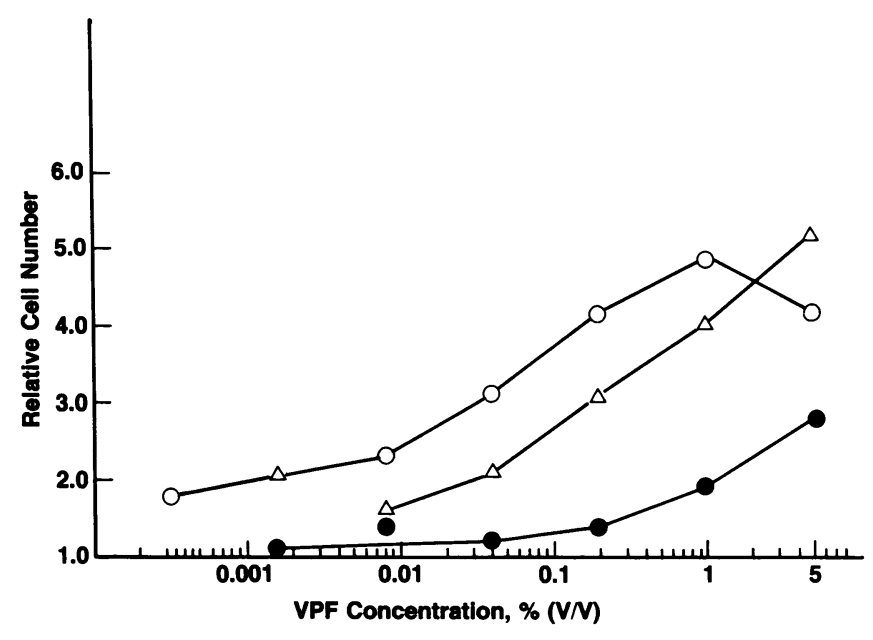

Figure 2. Effect on mitogenic activity of immunoadsorption of VPF

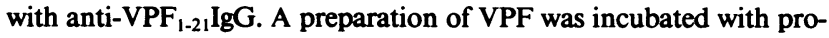
tein A-Sepharose IgG prepared from either anti-VPF I-21 $_{\text {serum }}(\bullet)$ or anti-FBS serum $(\Delta)$ as control. The resulting supernatants were diluted and incubated with BAE cells to determine the amount of mitogenic activity remaining in the samples. An untreated sample (o) was run for comparison. Each data point represents the mean of four replicates. SDs were smaller than the drawn symbols. Similar results have been obtained in two other experiments.

To determine if the various isoforms observed in the silver-stained gels were biologically active, VPF was subjected to preparative NEpHGE. The gels were fractionated and extracted, and each fraction assayed for both Miles permeability activity and growth promoting activity toward BAE cells. Fig. $4 \mathrm{~A}$ shows a photograph of the Coomassie blue-stained gel, Fig. $4 B$ shows the results of the permeability assay, and Fig. $4 C$ shows the results of the BAE cell growth assay. Both activities are present exclusively in fractions $20-33$, as are the stained
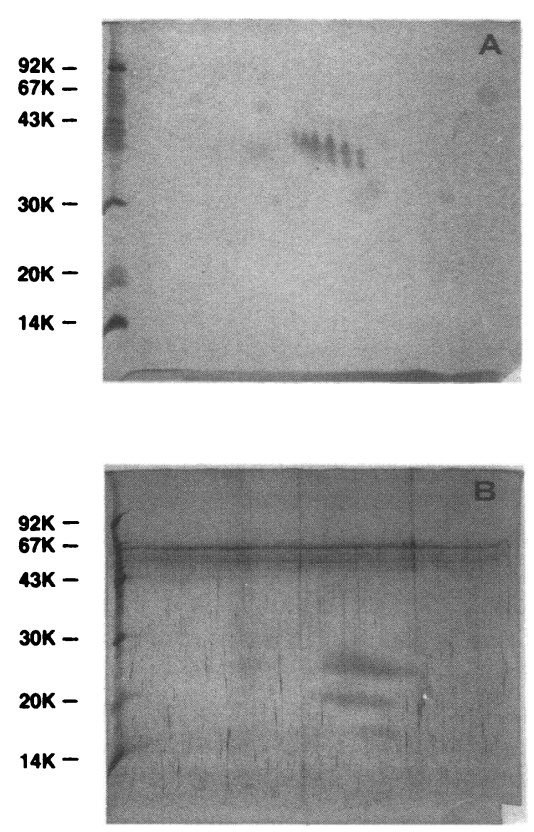

VPF bands in the original gel. It would appear from these results that all of the isoforms of VPF have both permeability enhancing and growth promoting activities.

Dose response and specificity of VPF mitogenic activity. Dose-response curves for VPF-stimulated growth and $\left[{ }^{3} \mathrm{H}\right]-$ thymidine incorporation into DNA using highly purified VPF are shown in Fig. 5. To examine the effect of VPF on cell growth, increasing amounts of VPF were added to sparse cul-
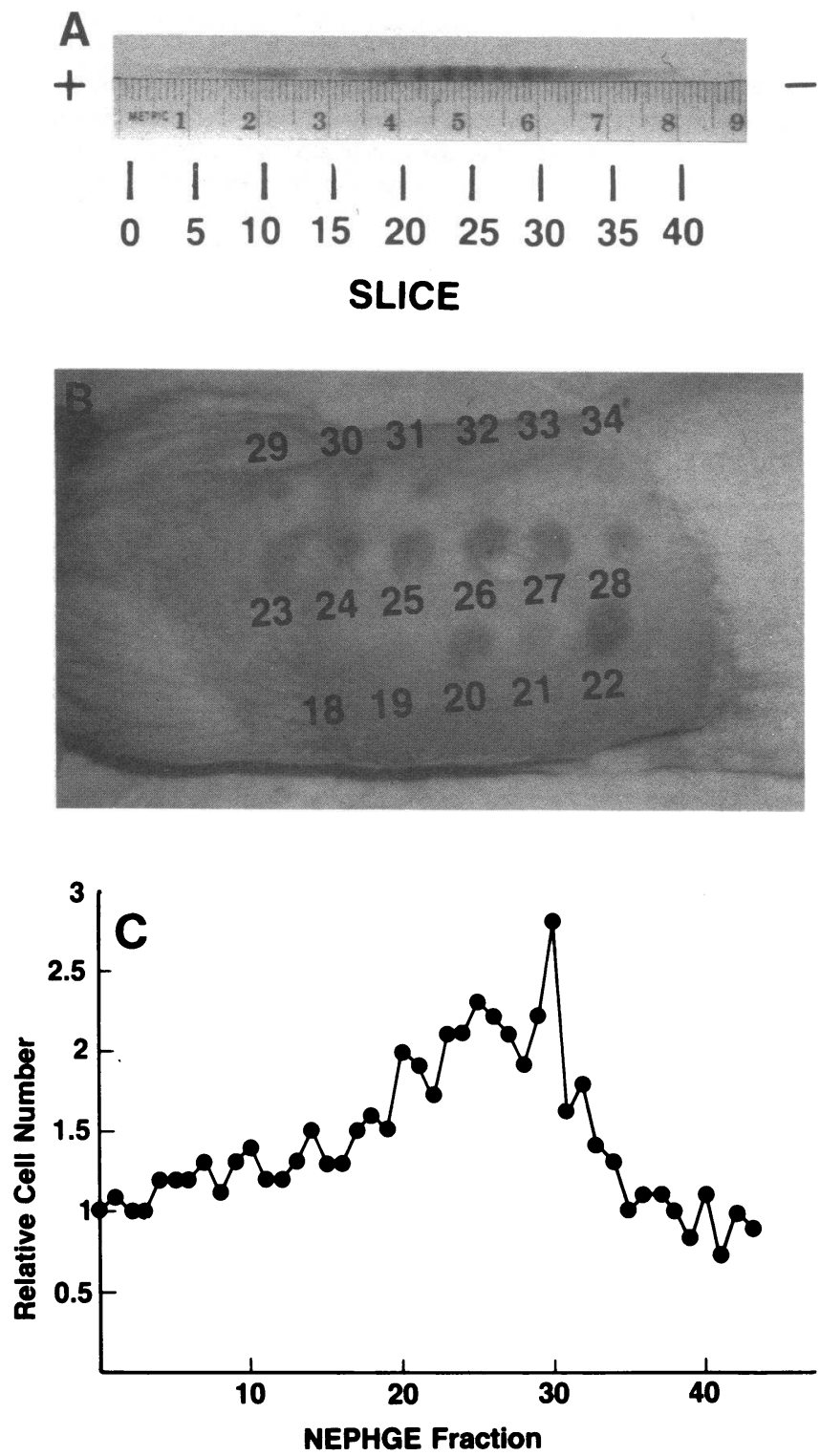

Figure 4. Preparative NEpHGE of active VPF. About $40 \mu \mathrm{g}$ of VPF from the $\mathrm{C} 18$ column was evaporated to dryness and dissolved in 50 $\mu 10.1 \%$ Triton X-100. Portions $(10 \mu \mathrm{l})$ were loaded onto identical gels (anode end) and subjected to NEpHGE. One of the gels was stained with Coomassie brilliant blue R250 $(A)$, and the other gel sliced into 2-mm fractions for extraction and assay. Each fraction was agitated at $37^{\circ} \mathrm{C}$ for $2 \mathrm{~h}$ in $400 \mu \mathrm{l}$ saline. After a further $1: 10 \mathrm{di}-$ lution, each fraction was assayed for VPF activity $(B)$. Only the active portion of the gel (fractions 18-34) are shown in this photo. In $C$, the fractions were assayed for endothelial cell growth factor activity after diluting 1:100. Each data point represents the mean of duplicate determinations for each fraction. The data are representative of two experiments. 


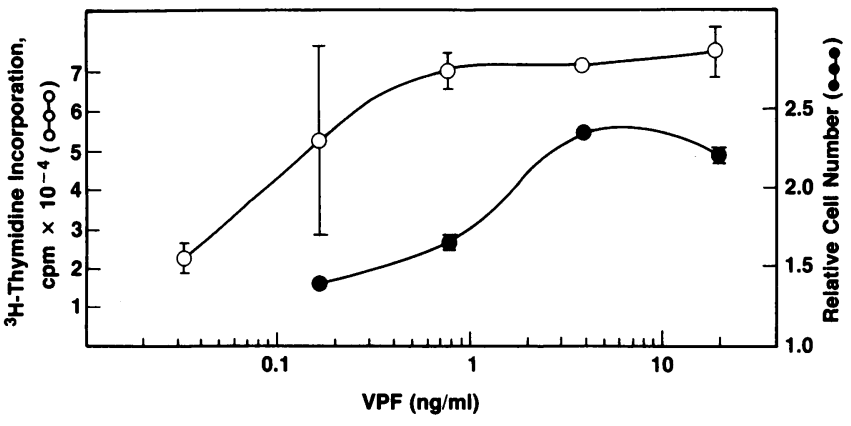

Figure 5. Effect of VPF concentration on $\left[{ }^{3} \mathrm{H}\right]$ thymidine incorporation and growth of bovine aortic endothelial cells. Different concentrations of VPF were added to cultures of BAE cells. For $\left[{ }^{3} \mathrm{H}\right]$ thymidine incorporation, confluent cultures were first deprived of serum for $24 \mathrm{~h}$ previous to VPF addition. $\left[{ }^{3} \mathrm{H}\right]$ Thymidine incorporation into acid-precipitable counts was then determined after $24 \mathrm{~h}$. To determine cell growth, VPF was added to sparse cultures in complete DME plus $10 \%$ calf serum, then the cell numbers determined after 5 d $(10,20)$.

tures of BAE cells in DME/10\% calf serum. Cell number was determined after $5 \mathrm{~d}$. Exposure to $0.5-10 \mathrm{ng} / \mathrm{ml} \mathrm{VPF}$ increased cell numbers in growth experiments by two- to threefold with a half-maximal growth stimulation observed at $\sim 2 \mathrm{ng} / \mathrm{ml}(5$ $\left.\times 10^{-11} \mathrm{M}\right) \mathrm{VPF}$. Confluent cultures of BAE cells in serumfree DME were used for determination of $\left[{ }^{3} \mathrm{H}\right]$ thymidine incorporation into acid-precipitable material after $1 \mathrm{~d}$. Increased $\left[{ }^{3} \mathrm{H}\right]$ thymidine incorporation by serum-deprived BAE cells into acid precipitable material occurred between 0.02 and 1 $\mathrm{ng} / \mathrm{ml}$, with half-maximal stimulation observed at $\sim 0.1$ $\mathrm{ng} / \mathrm{ml}\left(2.5 \times 10^{-12} \mathrm{M}\right) \mathrm{VPF}$. The $\left[{ }^{3} \mathrm{H}\right]$ thymidine response occurred at lower doses than did the growth response, perhaps due to the different conditions used for the two assays. The in vitro $\left[{ }^{3} \mathrm{H}\right]$ thymidine incorporation response was thus $\sim 400$ times more sensitive to VPF concentration than the in vivo permeability response. These results indicate that the mitogenic activity of VPF is at least as potent (if not more so) as the permeability-enhancing activity and that VPF is at least as potent as the FGFs $(22,23)$ in promoting endothelial cell growth.

The cellular specificity of the VPF-associated mitogenic activity was examined by comparing the $\left[{ }^{3} \mathrm{H}\right]$ thymidine incorporation by various cell types in serum-free medium supplemented with VPF to that obtained in serum-supplemented medium (Fig. 6). In this experiment, all cells were deprived of serum for $24 \mathrm{~h}$, then exposed for $24 \mathrm{~h}$ to either DME alone, DME containing excess VPF or DME containing $10 \%$ serum. As shown in Fig. 6, all of the cell types tested incorporated $\left[{ }^{3} \mathrm{H}\right]$ thymidine in response to the re-addition of serum, but only the BAE cells responded to the VPF in serum-free medium yielding a $\left[{ }^{3} \mathrm{H}\right]$ thymidine incorporation comparable to that obtained in serum-supplemented medium. In other experiments, VPF was also found to stimulate $\left[{ }^{3} \mathrm{H}\right]$ thymidine incorporation by human umbilical vein or bovine adrenal capillary endothelial cells. These results are in contrast to those obtained with FGF (24), EGF (25), or PDGF (26), which have been shown to stimulate several of the cell types studied here in addition to endothelial cells. Thus, unlike other growth factors, the mitogenic effect of VPF appears to be specific for vascular endothelial cells.

Because it was found that endothelial cell growth factor activity was associated with VPF, it was of interest to determine whether other factors, particularly those which affect endothelial cells, exhibited VPF-like activity. EGF (0.1-1,000 $\mathrm{ng} / \mathrm{ml})$, bFGF $(0.4-400 \mathrm{ng} / \mathrm{ml})$, aFGF $(5-50 \mathrm{ng} / \mathrm{ml})$, ILl $(0.08-80 \mathrm{ng} / \mathrm{ml})$, TGF $\beta(75-12,500 \mathrm{ng} / \mathrm{ml})$, TNF $\left(10^{2}-10^{6}\right.$ $\mathrm{ng} / \mathrm{ml})$, and PDGF $(6-6,000 \mathrm{ng} / \mathrm{ml})$ were tested in the Miles assay but none of these factors caused visible vessel leakage over the concentration ranges and during the time period tested $(5-15 \mathrm{~min}$ after injection). IL2 $(3-300 \mathrm{ng} / \mathrm{ml})$ produced a visible but significantly less intense response than VPF, confirming other observations that IL2 can enhance vascular permeability $(27,28)$. However, IL2, at $M_{\mathrm{r}}=17,000 \mathrm{D}(29)$, has a

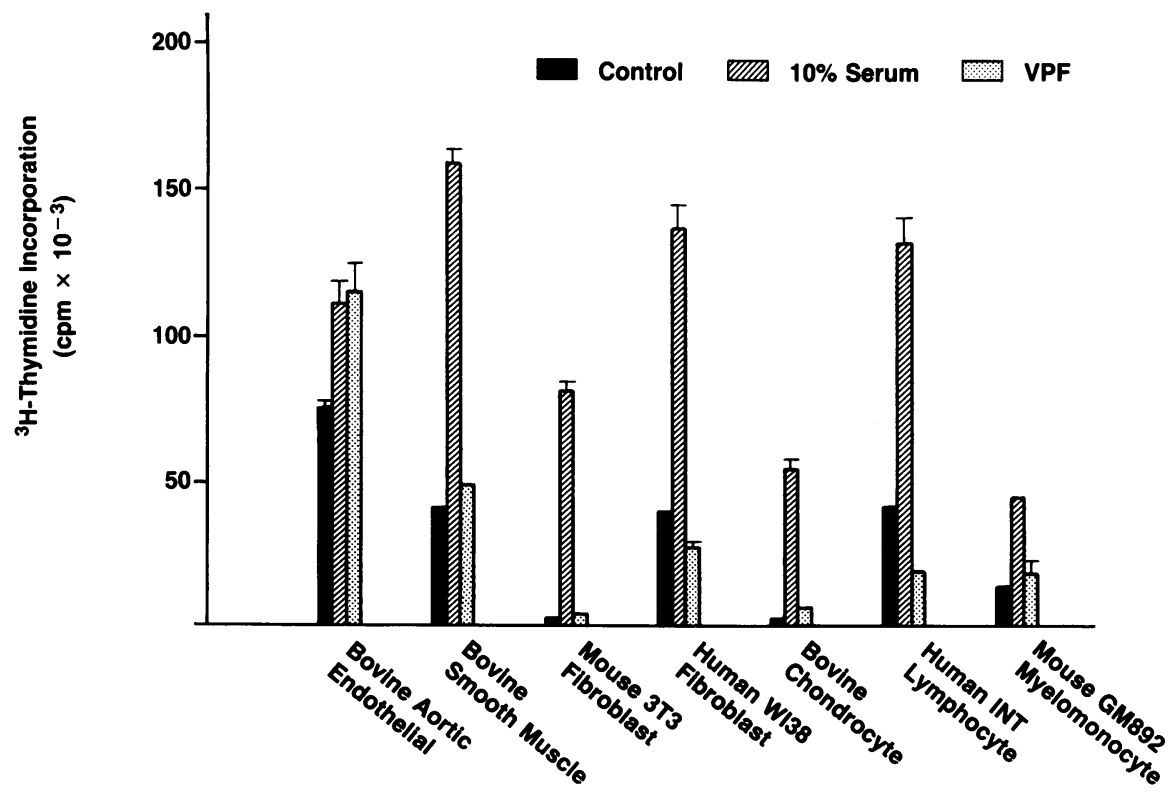

Figure 6. Cellular specificity of VPF-associated growth factor activity. Confluent cultures of cells were deprived of serum for $24 \mathrm{~h}$, at which time either fresh medium alone or medium supplemented with either $10 \%$ calf serum or VPF $(500 \mathrm{ng} / \mathrm{ml})$ was added. After an additional $24 \mathrm{~h},\left[{ }^{3} \mathrm{H}\right]$ thymidine was added to all cultures, and incorporation into acid precipitable counts determined after 2 more h. Each bar represents the mean \pm the range of duplicate determinations. The data are representative of two experiments. 


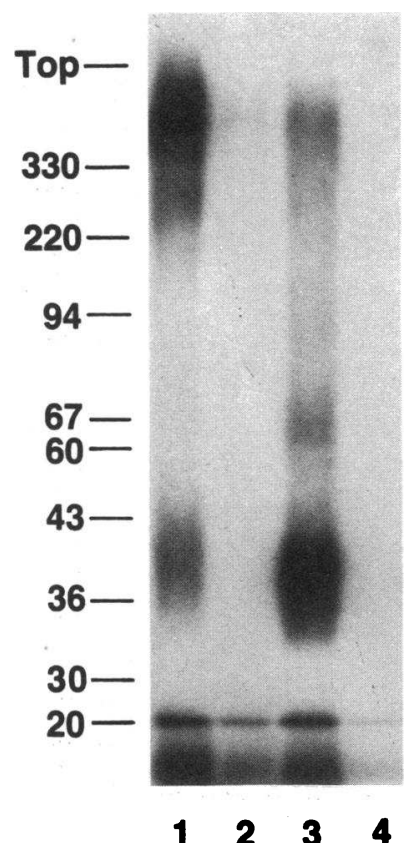

$\begin{array}{llll}1 & 2 & 3 & 4\end{array}$
Figure 7. Affinity labeling of HUE cells with ${ }^{125}$ I-VPF. HUE cells grown to near-confluency in $60-\mathrm{mm}^{2}$ plastic dishes were incubated with $1.0 \mathrm{nM}^{125} \mathrm{I}-\mathrm{VPF}$ at $4^{\circ} \mathrm{C}$ overnight (lanes 1 and 3 ), or in the presence of ${ }^{125} \mathrm{I}$-VPF plus $100 \mathrm{nM}$ unlabeled VPF (lane 2), or in the presence of ${ }^{125} \mathrm{I}-\mathrm{VPF}$ and a 1:8 dilution of rabbit antiserum to VPF (lane 4). At the end of the binding period, the cell layers were washed three times and the samples shown in lanes 1,2 , and 4 were cross-linked with DSS (31). Cross-linking reagent was omitted from lane 3. Cell membranes were solubilized in nonreducing SDSPAGE buffer (18) containing $1.0 \%$ Triton X-100, separated by SDSPAGE on a $7.5 \%$ gel, and autoradiographed at $-70^{\circ} \mathrm{C}$ for $3 \mathrm{~d}$. VPF was radioiodinated using the Bolton-Hunter procedure (32) to a specific activity of $1.3 \times 10^{7}$

$\mathrm{cpm} / \mu \mathrm{g}$. The rabbit antiserum, produced by multiple immunizations with VPF, blocked the permeability activity of VPF at a dilution of $1: 100$.

different molecular weight from VPF $\left(M_{\mathrm{r}} \sim 40 \mathrm{kD}\right)$. Furthermore, the $\mathrm{NH}_{2}$-terminal sequence for the first 36 amino acids of VPF is also distinct from IL2 (29) and other known proteins.

Conversely, histamine, bradykinin, and serotonin, which are mediators of vessel permeability (30) had no effect on cell growth when added to cultures of BAE cells at concentrations between $10^{-10}$ and $10^{-5} \mathrm{M}$. Positive controls with VPF produced two- to threefold increases in cell number.

Binding of ${ }^{125} I-V P F$ to endothelial cells. To detect the presence of specific cell surface receptors for VPF on endothelial cells, purified VPF was labeled with ${ }^{125} \mathrm{I}$, incubated at $4^{\circ} \mathrm{C}$ with human umbilical vein endothelial cells (HUE cells) at a concentration of $1 \mathrm{nM}$ and then treated with the chemical crosslinking reagent disuccinimidyl suberate (DSS). Samples were then analyzed by SDS-PAGE and autoradiography. Fig. 7 (lane 1) shows that ${ }^{125} \mathrm{I}-\mathrm{VPF}$ formed an $M_{\mathrm{r}}>330-\mathrm{kD}$ complex with an endothelial cell surface protein. Complex formation was blocked in the presence of excess unlabeled VPF (lane 2) or rabbit anti-VPF serum (lane 4) but not by the addition of 500-1,500-fold excesses of aFGF, bFGF, EGF, PDGF, IL2, or TNF (not shown). Moreover, histamine $\left(10^{-4} \mathrm{M}\right)$, serotonin $\left(10^{-4} \mathrm{M}\right)$, bradykinin $\left(10^{-6} \mathrm{M}\right)$ or platelet-activating factor $\left(10^{-8} \mathrm{M}\right)$ also did not compete with ${ }^{125} \mathrm{I}$-VPF binding to the HUE cells. Upon reduction with $\beta$-mercaptoethanol, the broad cross-linked band at $M_{\mathrm{r}}>330 \mathrm{kD}$ of lane 1 became less dispersed, but did not change molecular weight significantly, whereas the uncomplexed $M_{\mathrm{r}} 36-40-\mathrm{kD}$ VPF band itself was reduced to $M_{\mathrm{r}}=20$ - and 24-kD subunits (data not shown). The small amount of higher molecular weight complex seen in the uncrosslinked sample (lane 3) also disappeared upon reduction, suggesting that intact disulfides might be necessary for complex formation. Specific crosslinking was observed with as little as $10 \mathrm{pM}$ VPF indicating that the affinity of the binding protein for VPF was very high. This was confirmed by
Scatchard analysis of binding experiments in which a $K_{d}$ of $\sim 50 \mathrm{pM}$ was obtained for ${ }^{125}$ I-VPF binding to HUE cells (unpublished observations). Cross-linking experiments using BAE cells instead of HUE cells produced similar results, but the efficiency of binding was somewhat lower than that observed with the HUE cells. These results demonstrate that VPF can interact directly with endothelial cells by forming a high affinity complex with a cell surface protein, possibly a VPF receptor.

Effect of VPF on angiogenesis in healing bone grafts. Because VPF appeared to be a specific endothelial cell mitogen, it seemed possible that VPF might also promote angiogenesis in vivo. To test this, VPF was administered via osmotic pumps over a 14-d period into healing mandibular bone grafts in rabbits (15). Fig. 8 shows representative sections containing silicone-preserved blood vessels from contralateral control and VPF treated bone grafts from the same animal. The VPFtreated grafts clearly have more blood vessels, particularly toward the center of the grafts near the outlet of the tubing leading from the pump. This effect was seen in three out of four rabbits.

Effect of VPF on angiogenesis in the rat cornea. VPF was tested at doses between $0.4 \mathrm{ng}$ and $1 \mu \mathrm{g}$ in a rat cornea angiogenesis assay. Angiogenesis was absent in corneas receiving albumin alone, or at VPF doses of 0.4 and 2 ng. Fig. 9 shows a positive angiogenic response from one of two corneas receiving an implant containing $20 \mathrm{ng}$ VPF. A similar but stronger response was observed in two of two animals receiving $200 \mathrm{ng}$ VPF. The corneas were clear, indicating the absence of signifcant inflammation. This was confirmed by histological examination of corneal sections in which few neutrophils or other inflammatory cells were noted. In contrast, implants containing $1 \mu \mathrm{g}$ VPF produced an intense angiogenic response, which was accompanied by marked clouding of the cornea, indicating inflammation. Thus, the lower doses of VPF induced angiogenesis in the cornea without evidence of inflammation whereas at a higher dose, VPF was inflammatory.

\section{Discussion}

These data demonstrate that purified VPF can interact directly with endothelial cells in vitro and that administration of VPF in vivo results in angiogenic responses in two different model systems. The action of VPF may be mediated by the putative high-affinity VPF receptor identified here in chemical crosslinking experiments. This interaction was highly specific in that a variety of other growth factors and vasoactive agents did not affect binding. It remains to be determined, however, whether or not the vascular leakage or angiogenic responses observed in vivo in response to VPF are due entirely to direct action of VPF on endothelial cells, or if other secondary effectors are also involved. One such secondary effector could be fibrin, which has been shown to be angiogenic, and which could be deposited at sites of VPF-mediated extravasation of fibrinogen (33).

The mitogenic activity discovered in association with VPF was unexpected. In light of the extensive structural heterogeneity observed for VPF in one- and two-dimensional electrophoretic systems, and in the chromatographic systems used during purification, it was extremely important to determine if both activities emanated from the protein identified as VPF and not 


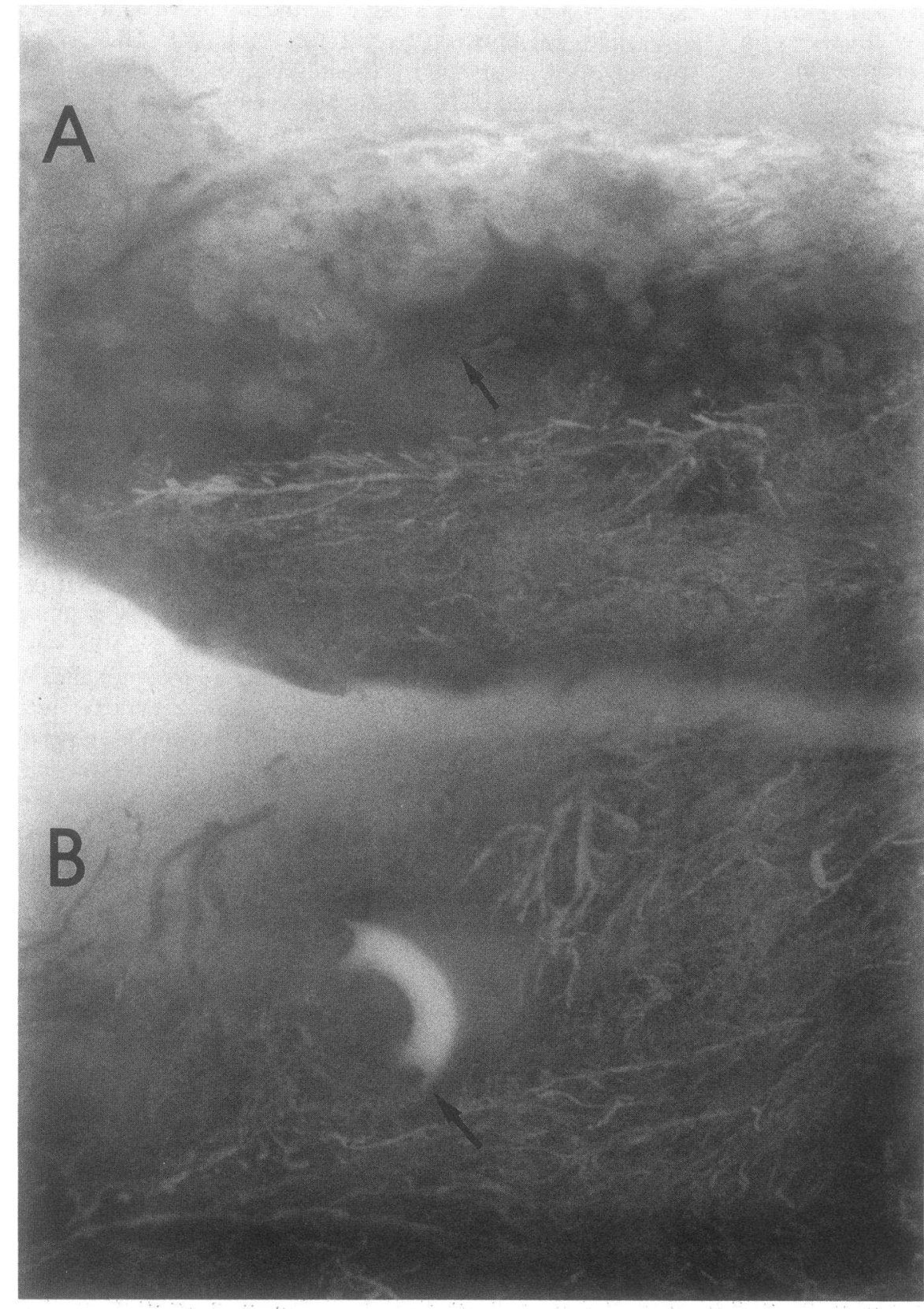

Figure 8. Effect of VPF on angiogenesis in healing bone grafts. The angiogenic activity of VPF was tested in a model designed to measure neovascularization in healing mandibular bone grafts (15). (A) shows a control bone graft in which the musclegraft junction is readily apparent. The delivery tube (arrow), is partly visible near the center of the graft. Few vessels are present within the graft itself. $(B)$ shows a VPFtreated bone graft. Vessels have proliferated into the graft from the overlaying muscle and appear to be growing toward the VPF delivery tube (arrow). from a contaminant. Several lines of evidence lead to the conclusion that VPF itself is the mitogen in these preparations. First, the preparations of VPF used in these studies were highly purified, and estimated to be $>90 \%$ pure by SDS-PAGE and silver staining. Because extremely low concentrations of VPF $\left(\sim 10^{-12} \mathrm{M}\right)$ were needed to elicit $\left[{ }^{3} \mathrm{H}\right]$ thymidine incorporation by the endothelial cells, a contaminant present in lower concentrations would be even more potent than this. Although not impossible, such a factor has not been previously described. Secondly, both activities have molecular masses of $\sim 40 \mathrm{kD}$ as determined by preparative SDS-PAGE, substantially different from most of the previously described endothelial cell mitogens (21). Thirdly, multiple isoforms of VPF were observed with apparent pIs $\geq 8$. Both types of activity were observed to be associated with all of the isoforms extracted after preparative NEpHGE. Thus, not only did the two activities have the same molecular weight, but they also had the same disperse charge properties. Fourth, sequence analysis revealed only the presence of the VPF sequence that is unrelated to other known growth factors or permeability enhancers (7a). Fifth, immunoadsorbtion using antipeptide IgG directed against the $\mathrm{NH}_{2}$ terminus of VPF removed both activities. This experiment most strongly suggests that both activities emanate from proteins sharing the same $\mathrm{NH}_{2}$ terminal amino acid sequence, and therefore almost certainly from the protein identified as VPF.

VPF as prepared from large-scale cultures of guinea pig line 10 cells, is a physically heterogeneous protein. Several sized bands of $\sim M_{\mathrm{r}}$ 38-40 kD were observed in SDS-PAGE, and several isoforms with pIs $\geq 8$ were observed in NEpHGE. The available evidence suggests that native VPF is a dimer composed of disulfide-linked subunits, each with the same $\mathrm{NH}_{2-}$ terminal amino acid sequence (7a). This conclusion is derived from the sequencing of intact VPF, in which only one se- 


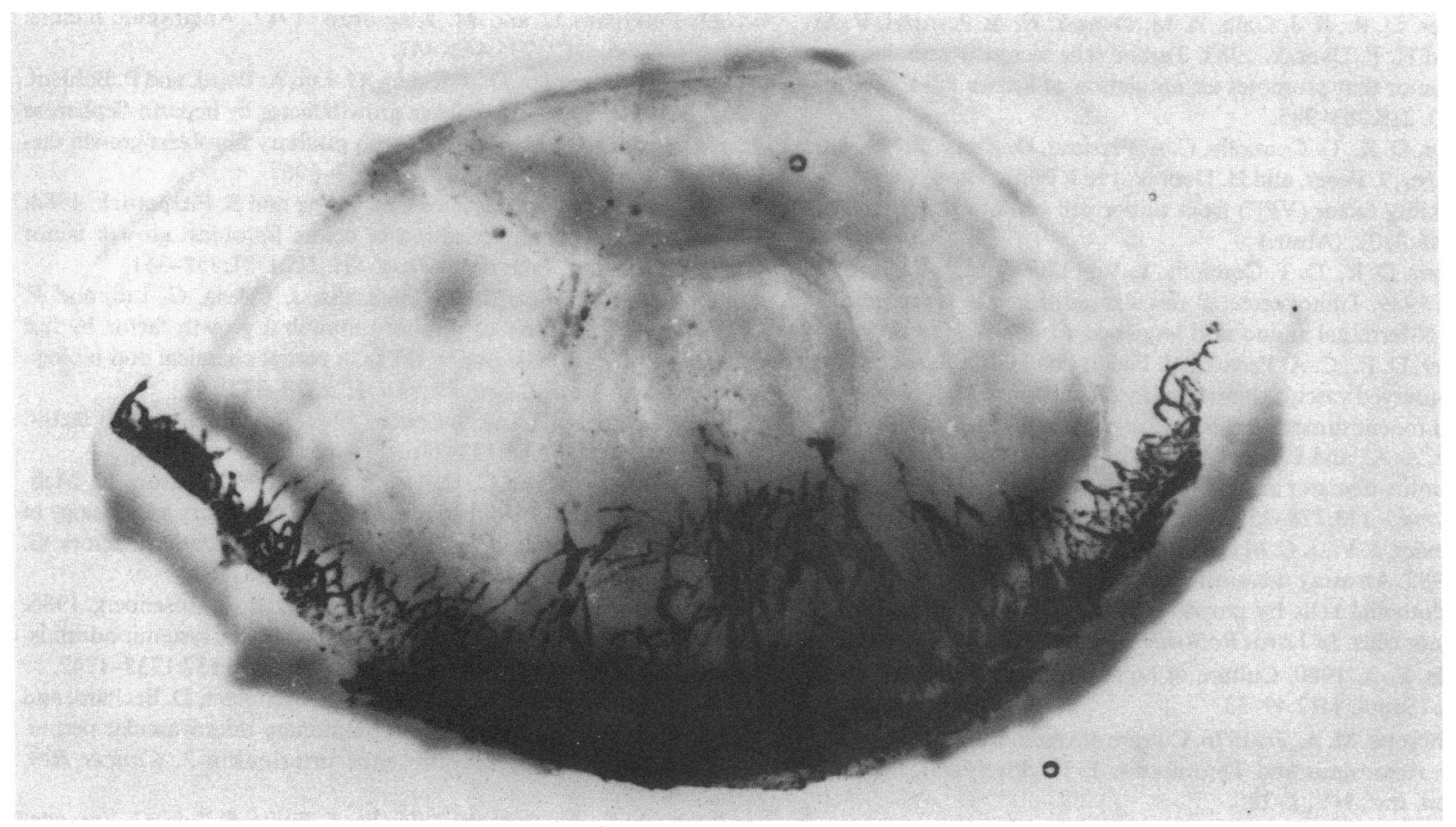

Figure 9. Effect of VPF on angiogenesis in the rat cornea. Hydron pellets containing VPF were implanted in rat corneas. Shown is a 7-d response to $20 \mathrm{ng}$ VPF.

quence is obtained, from sequencing the subunits individually (7a), and from reaction of the subunits with antipeptide antibodies in Western blots (7a). The subunits, however, vary in size from $\sim M_{\mathrm{r}} 18$ to $24 \mathrm{kD}$. Sequencing did reveal that $\sim 30 \%$ of the VPF molecules in some preparations were missing the first or first three amino acids. This modification could not account for the size or charge heterogeneity (the first three amino acids are neutral). Thus, the physical differences in size and charge among the forms of VPF are at present unexplained, but could arise from alternate glycosylation, proteolysis, or other modifications in parts of the VPF molecule other than the $\mathrm{NH}_{2}$ terminus. All of the isoforms had both permeability-enhancing and growth-promoting activities, but it is not known if all the forms are equipotent.

The production of angiogenic factors by various tumors has been extensively described $(21,34)$, but it is important to point out that VPF appears to be distinct from any of these previously described factors. The $\mathrm{NH}_{2}$-terminal sequence of VPF is also distinct from the recently described endothelial cell PDGF (35). Because VPF has been shown to be secreted by a wide variety of tumor cell types (8), it is possible that VPF might itself serve to stimulate vessel growth towards tumors in vivo.

Presently, there is no evidence to link VPF with inflammation. However, it is interesting to note that two of the known biological activities of VPF, namely vascular permeability enhancement and promotion of neovascularization, are also often associated with inflammation. One of the major components of the inflammatory response is an increase in vascular permeability (36). Endothelial cell proliferation and neovascularization also may accompany inflammation (37). Thus, both of the activities of VPF make it a candidate to be an inflammatory mediator. This hypothesis is under investigation. It will be of interest to determine what role, if any, VPF might play in these processes and if VPF might play a role in related phenomena such as wound healing.

\section{Acknowledgments}

We thank Dr. S. Joseph Leibovich (Northwestern University, Chicago, IL) for performing cornea angiogenesis assays, Dr. Steven Adams for providing the synthetic VPF peptide and Dr. Harold Dvorak and Dr. Donald Senger (Beth Israel Hospital, Boston, MA) for generous advice and help during this work. We are grateful to Roger Monsell (Monsanto Co.) for assistance in growing large-scale cultures of cells.

Note added in proof. After the present manuscript was accepted for publication, a report by Ferrara, N., and W. J. Henzel appeared in Biochem. Biophys. Res. Commun. 161:851-858 that describes the isolation from bovine pituitary cells of a growth factor with an identical $\mathrm{NH}_{2}$-terminal sequence as VPF.

\section{References}

1. Brown, L. F., B. Asch, S. Harvey, B. Buchinski, and H. Dvorak. 1988. Fibrinogen influx and accumulation of cross-linked fibrin in mouse carcinomas. Cancer Res. 48:1920-1925.

2. Gerlowski, L. E., and R. K. Jain. 1986. Microvascular Permeability of Normal and Neoplastic Tissues. Microvasc. Res. 31:288-305.

3. O'Connor, S. W., and W. F. Bale. 1984. Accessibility of circulating immunoglobulin $\mathrm{G}$ to the extravascular compartment of solid rat tumors. Cancer Res. 44:3719-3723.

4. Song, C. W., and S. H. Levitt. 1971. Quantitative study of vascularity in Walker carcinoma 256. Cancer Res. 31:587-589.

5. Dvorak, H. F., N. S. Orenstein, and A. M. Dvorak. 1981. Tumor-secreted mediators and the tumor microenvironment: relationship to immunological surveillance. In Lymphokines. Edgar Pick, editor. Academic Press, Inc., New York. 2:203-233. 
6. Senger, D. R., S. J. Galli, A. M. Dvorak, C. A. Perruzzi, V. S. , Harvey, and H. F. Dvorak. 1983. Tumor cells secrete a vascular permeability factor that promotes accumulation of ascites fluid. Science (Wash. DC). 219:983-985.

7. Senger, D. R., D. Connolly, C. A. Perruzzi, D. Alsup, R. Nelson, R. Leimgruber, J. Feder, and H. Dvorak. 1987. Purification of a vascular permeability factor (VPF) from tumor cell conditioned medium. Fed. Proc. 46:2102. (Abstr.)

7a. Senger, D. R., D. T. Connolly, L. Van De Water, J. Feder, and H. Dvorak. 1989. Tumor-secreted vascular permeability factor: purification and N-terminal amino acid sequence. Cancer Res. In press.

8. Senger, D. R., C. A. Perruzzi, J. Feder, and H. F. Dvorak. 1986. A highly conserved vascular permeability factor secreted by a variety of human and rodent tumor cell lines. Cancer Res. 46:5629-5632.

9. Miles, A. A., and E. M. Miles. 1952. Vascular reactions to histamine, histamine-liberator and leukotaxine in the skin of guinea-pigs. $J$. Physiol. (Lond.). 118:228-257.

10. Olander, J. V., J. C. Marasa, R. C. Kimes, G. M. Johnston, and J. Feder. 1982. An assay measuring the stimulation of several types of bovine endothelial cells by growth factor(s) derived from cultured human tumor cells. In Vitro (Rockville). 18:99-107.

11. Jaffe, E. A. 1980. Culture of human endothelial cells. Transplant. Proc. (Suppl. 1)12:49-53.

12. Gimbrone, M. A., Jr. 1976. Culture of vascular endothelium. In Progress in Hemostasis and Thrombosis. T. H. Spaet, editor. Grune and Stratton, Inc., NY. 1-28.

13. Knedler, A., and R. G. Ham. 1987. Optimized medium for clonal growth of human microvascular endothelial cells with minimal serum. In Vitro Cell. Dev. Biol. 23:481-490.

14. Hoshi, H., and W. L. McKeehan. 1986. Isolation growth requirements, cloning, prostacyclin production and life-span of human adult endothelial cells in low serum culture medium. In Vitro Cell. Dev. Biol. 22:51-56.

15. Eppley, B. L., M. Doucet, D. T. Connolly, D. Heuvelman, and J. Feder. 1988. Enhancement of angiogenesis by bFGF in mandibular bone graft healing in the rabbit. Oral Maxillofacial Surg. 46:391-398.

16. Polverini, P. J., and S. J. Leibovich. 1984. Induction of neovascularization in vivo by tumor-associated macrophages. Lab. Invest. 51:635-642.17.

17. Klagsbrun, M., J. Sasse, R. Sullivan, and J. Smith. 1986. Human tumor cells synthesize an endothelial cell growth factor that is structurally related to basic fibroblast growth factor. Proc. Natl. Acad. Sci. USA. 83:2448-2452.

18. Laemmli, U. K. 1970. Cleavage of structural proteins during the assembly of the head of bacteriophage T4. Nature (Lond.). 227:680-685.

19. Morrissey, J. H. 1981. Silver stain for proteins in polyacrylamide gels: a modified procedure with enhanced uniform sensitivity. Anal. Biochem. 117:307-310.

20. Connolly, D. T., M. B. Knight, N. K. Harakas, A. J. Wittwer, and J. Feder. 1986. Determination of the number of endothelial cells in culture using an acid phosphatase assay. Anal. Biochem. 152:136140.
21. Folkman, J., and M. Klagsbrun. 1987. Angiogenic factors. Science (Wash. DC). 235:442-447.

22. Gospodarowicz, D., J. Cheng, G. Lui, A. Baird, and P. Bohlent. 1984. Isolation of brain fibroblast growth factor by heparin-Sepharose affinity chromatography: identity with pituitary fibroblast growth factor. Proc. Natl. Acad. Sci. USA. 81:6963-6967.

23. Thomas, K. A., M. Rios-Candelore, and S. Fitzpatrick. 1984. Purification and characterization of acidic fibroblast growth factor from bovine brain. Proc. Natl. Acad. Sci. USA. 81:357-361.

24. Gospodarowicz, D., S. Massoglia, J. Cheng, G. Lui, and P. Bohlen. 1985. Isolation of pituitary fibroblast growth factor by fast protein liquid chromatography (FPLC): partial chemical and biological characterization. J. Cell. Physiol. 122:323-332.

25. Carpenter, G., and S. Cohen. 1979. Epidermal growth factor. Annu. Rev. Biochem. 48:193-216.

26. Westermark, B., C.-H. Heldin, B. Ek, A. Johnson, K. Mellstrom, M. Nister, and A. Wasteson. 1983. Biochemistry and biology of platelet-derived growth factor. In Growth and Maturation Factors. G. Guroff, editor. John Wiley \& Sons, New York. 83-87.

27. Rosenstein, M., S. E. Ettinghausen, and S. A. Rosenberg. 1986. Extravasation of intravascular fluid mediated by the systemic administration of recombinant interleukin 2. J. Immunol. 137:1735-1742.

28. Fairman, R. P., F. L. Glauser, R. E. Merchant, D. Bechard, and A. A. Fowler. 1987. Increase of rat pulmonary microvascular permeability to albumin by recombinant interleukin-2. Cancer Res. 47:3528-3522.

29. Kashima, N., C. Nishi-Takaoka, T. Fujita, S. Taki, G. Yamada, J. Hamuro, and T. Taniguchi. 1985. Unique structure of murine interleukin-2 as deduced from cloned cDNAs. Nature (Lond.). 313:402404.

30. Smedegard, G. 1985. Mediators of vascular permeability in inflammation. Prog. Appl. Microcirc. 7:96-112.

31. Olwin, B. B., and S. D. Hauschka. 1986. Identification of the fibroblast growth factor receptor of Swiss 3T3 cells and mouse skeletal muscle fibroblast. Biochemistry. 25:3487-3492.

32. Bolton, A. E., and W. M. Hunter. 1973. The labeling of proteins to higher specific radioactivities by conjugation to a I-containing acylating agent. Biochem. J. 133:529-539.

33. Dvorak, H. F., V. S. Harvey, P. Estrella, L. F. Brown, J. McDonagh, and A. Dvorak. 1987. Fibrin containing gels induce angiogenesis: implications for tumor stroma generation and wound healing. Lab. Invest. 57:673-686.

34. Folkman, J. 1985. Tumor angiogenesis. Adv. Cancer Res. 43:175-203.

35. Ishikawa, F., K. Miyazono, U. Hellman, H. Drexler, C. Wernstedt, K. Hagiwara, K. Usuki, F. Takaku, W. Risau, and C. Heldin. 1989. Identification of angiogenic activity and the cloning and expression of platelet-derived endothelial cell growth factor. Nature (Lond.). 338:557-562.

36. Ryan, G. B., and G. Majno. 1977. In Inflammation. The Upjohn Company, Kalamazoo, MI. 12-23.

37. Polverini, P. J., R. S. Cotran, and M. M. Sholley. 1977. Endothelial proliferation in the delayed hypersensitivity reaction: an autoradiographic study. J. Immunol. 118:529-532. 